\title{
PENGEMBANGAN INSTRUMEN Test of Scientific Literacy Skills (TOSLS) BERBASIS DARING PADA PEMBELAJARAN IPA UNTUK MENGUKUR LITERASI SAINS
}

\author{
Arfiati Ulfa Utami ${ }^{1 *}$ \\ Universitas PGRI Banyuwangi, Banyuwangi, Indonesia \\ *Corresponding Author: arfiatiuniba@gmail.com
}

DOI: $10.24929 /$ lensa.v11i2.157

Received: 23 Maret 2021

Revised: 16 Oktober 2021

Accepted: 17 Oktober 2021

\begin{abstract}
ABSTRAK
Pentingnya mengukur literasi sains pada pembelajaran IPA merupakan salah satu capaian pembelajaran dalam menganalisis permasalahan dalam kehidupan nyata. Tujuan penelitian adalah mengembangkan instrumen penilaian Test of Scientific Literacy Skills (TOSLS) berbasis daring yang akurat digunakan sebagai salah satu bentuk inovasi instrumen pada pembelajaran IPA. Penelitian ini termasuk penelitian pengembangan menggunakan model 4-D. Subjek uji coba yaitu siswa kelas VIII SMP Negeri 1 Srono, Kabupaten Banyuwangi. Hasil penelitian yaitu (1) Terdapat 40 soal yang dapat dikatakan valid, (2) Nilai koefisien alpha menunjukkan bahwa nilai reliabilitas 0,8 yang berarti instrument dapat dikatakan baik dan reliable, (3) Hasil ujicoba diperoleh rata-rata dari indikator I dan II yaitu 62,84. Terdapat skor tertinggi yaitu 80,92 pada indikator mengidentifikasi argument saintifik yang tepat, dan terdapat skor terendah yaitu 40,91 pafa indikator membuat grafik data.
\end{abstract}

Kata kunci: TOSLS, daring, literasi sains

\begin{abstract}
The importance of measuring scientific literacy in science learning is one of the learning achievements in analyzing real-life problems. The purpose of this research is to develop an online-based Test of Scientific Literacy Skills (TOSLS) assessment instrument that is accurate to be used as a form of instrument innovation in science learning. This research includes development research using the 4-D model. The subjects of the experiment were the eighth grade students of SMP Negeri 1 Srono, Banyuwangi Regency. The results of the study are (1) There are 40 questions that can be said to be valid, (2) The alpha coefficient value shows that the reliability value is 0.8 which means the instrument can be said to be good and reliable, (3) The test results obtained an average of indicators $I$ and II ie 62.84. There is the highest score of 80.92 on the indicator of identifying the right scientific argument, and the lowest score of 40.91 on the indicator of making data graphs.
\end{abstract}

Keywords: TOSLS, daring, scientific literacy

\section{PENDAHULUAN}

Pembelajaran di tengah pandemi memberi dampak terhadap sektor Pendidikan di Indonesia. Kegiatan belajar mengajar yang dilakukan secara daring sering membuat siswa bosan, guru juga dituntut untuk membuat rencana pembelajaran yang praktis serta mudah diimplementasikan pada siswa khususnya pada pembelajaran IPA. Pembelajaran IPA harus menjawab tantangan-tantangan dalam kehidupan nyata terkait dengan gejala alam dan kinerja ilmiah, dengan demikian pembelajaran IPA dapat dikatakan harus sesuai dengan hakikatnya yaitu siswa diminta untuk melakukan proses pengamatan terkait gejala alam, kemudian 
melakukan suatu penelitian atau riset dan dapat menyimpulkan sebagai produk. Hal ini akan membentuk sikap ilmiah siswa (Sulthon, 2016).

Literasi sains dalam pembelajaran IPA merupakan poin penting menyongsong lahirnya era baru. Literasi sains menjadi target dalam pembelajaran yang harus dicapai karena mampu melatihkan siswa dalam menyelesaikan permasalahan yang berkaitan dengan tuntutan zaman yang semakin rumit. Pembelajaran ini menuntut ketercapaian penguasaan kemampuan dan keterampilan sains di dalam kehidupan nyata. Hal ini harus diimbangi dengan sistem pembelajaran yang kondusif, kreatif, menyenangkan, menantang, dan mampu memberikan semangat untuk terlibat dalam pembelajaran (Hidayati, 2018). Selain itu guru harus mampu membuat instrument penilaian literasi sains, hal ini digunakan sebagai referensi guru untuk mengetahui kemampuan siswa.

Salah satu instrumen yang dikembangkan untuk mengukur keterampilan sains yaitu Instrumen TOSLS. Instrumen ini digunakan untuk mengukur literasi ilmiah siswa dalam bidang IPA yang dikembangkan oleh Gormally, dkk (2012). Terdapat 2 indikator dan 9 sub indikator yaitu : (1) Siswa mampu mengetahui konsep ilmiah, dan (2) Siswa mampu mengolah data ilmiah. Instrumen tersebut dikembangkan dengan memanfaatkan teknologi informasi atau dilakukan secara daring. Adapun sub indikator yaitu (1)Siswa mampu merumuskan pernyataan saintifik, (3) Siswa mampu menggunakan referensi dengan tepat, (3) Siswa mampu melakukan analysis masalah, (4) siswa mampu memahami desain penelitian, (5) siswa mampu membuat grafik data, (6) siswa mampu menginterpretasikan data, (7) Siswa mampu memecahkan masalah menggunakan statistik probabilitas, (8) siswa mampu menginterpretasikan statistika dalam suatu penelitian, (9) siswa mampu membuat kesimpulan.

Penilaian dalam pembelajaran merupakan suatu upaya untuk memperoleh informasi terkait perkembangan kemampuan ataupun keterampilan siswa sebagai bahan evaluasi belajar siswa. Evaluasi dalam pembelajaran penting dilakukan mengingat sebagai bahan untuk mengambil keputusan (Imania, 2019). Hasil pengamatan di sekolah bahwasanya belum adanya inovasi dalam membuat instrument penilaian khususnya dalam bidang IPA. Maka dari itu peneliti melakukan pengembangan instrument penilaian TOSLS berbasis daring untuk mengukur literasi sains. Literasi sains harus telah dilatihkan dan dilakukan evaluasi meskipun dalam kondisi pandemi. Pengembangan instrument ini dilakukan secara daring agar memudahkan siswa dalam mengerjakannya, karena siswa masih dalam kegiatan pembelajaran daring. Menurut Mendikbud, Kurikulum 2013 mempunyai empat elemen yaitu, standar isi mencakup materi dan tingkat kompetensi, standar proses pembelajaran, kompetensi lulusan atau kemampuan lulusan, dan standar penilaian evaluasi. Untuk mencapai keempat elemen tersebut membutuhkan instrument yang tepat untuk mencapai target ketercapaian siswa pada keempat aspek tersebut. Standar dalam penilaian merupakan suatu elemen perubahan yang wajib menjadi perhatian (Dewi dkk, 2016).

Pentingnya melakukan penelitian pengembangan instrument penilaian adalah sebagai bentuk inovasi dalam pembelajaran IPA, inovasi dalam mengembangkan perangkat penilaian harus disesuaikan dengan tujuan dan target pembelajaran. Dalam penelitian ini literasi sains menjadi target dalam pengembangan instrument. Dalam riset ini indikator pencapaiannya sesuai dengan indikator Gormally, karena instrument yang digunakan untuk mengukur literasi sains yaitu TOSLS. Tahapan pengembangannya yaitu (1) analisis masalah pembelajaran, (2) analisis kebutuhan siswa, (3) desain produk instrument TOSLS, (4) uji validasi instrumen, (5) revisi instrument TOSLS, (6) Uji coba terbatas, (7) Revisi produk TOSLS, (8) aplikasi produk ke sekolah (Sugiyono, 2015).

\section{METODE}

Penelitian ini merupakan penelitian pengembangan yang bertujuan untuk menghasilkan produk. Produk tersebut adalah instrumen Test of Scientific Litercy Skills (TOSLS) berbasis daring pada pembelajaran IPA untuk mengukur literasi sains. Ujicoba dilaksanakan di SMP Kabupaten Banyuwangi tanggal 09-12 November 2020. 
Prosedur penelitian meliputi; studi pendahuluan, penyusunan spesifikasi instrument, menulis instrument, telaah instrument, uji coba, analisis ujicoba, merakit isntrumen, melakukan pengukuran, penafsiran hasil pengukuran, diseminasi (Sukmasari, 2017). Metode pengumpulan data menggunakan wawancara, observasi, serta angket. Instrument penelitian meliputi pedoman wawancara, lembar observasi, dan angket. Teknik analisis data yang digunakan analisis validasi isi, reliabilitas, serta instrument TOSLS sesuai oleh Gormally et al (2012) pada Tabel 1 di bawah ini.

Tabel 1. Kriteria Interpretasi Skor

\begin{tabular}{cc}
\hline Interval Kriteria Skor & Kriteria \\
\hline $80 \leq x \leq 100$ & Sangat memuaskan \\
\hline $66 \leq x \leq 79$ & Memuaskan \\
\hline $56 \leq x \leq 65$ & Cukup \\
\hline $40 \leq x \leq 55$ & Kurang \\
\hline $30 \leq x \leq 39$ & Sangat Kurang \\
\hline
\end{tabular}

\section{HASIL DAN PEMBAHASAN}

Pengembangan instrument yang telah dilakukan mengacu pada indikatorindikator yang diadopsi dari Gormally. Materi yang digunakan dalam penelitian ini meliputi gaya dan hukum newton di kelas VIII SMP Semester 2 mengikuti acuan Kurikulum baru. Aplikasi yang digunakan dalam instrument penilaian TOSLS berbasis daring yaitu menggunakan aplikasi google form. Soal yang sudah dinyatakan valid akan ditampilkan di google form kemudian diujicobakan pada siswa. Tampilan soal seperti gambar di bawah ini

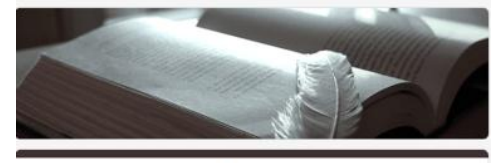

Test of Scientific Literacy Skills (TOSLS)

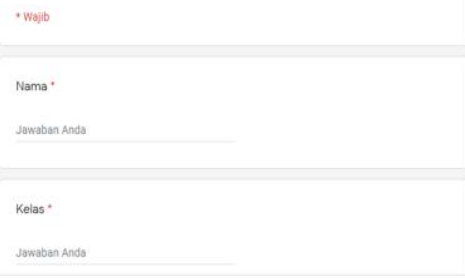

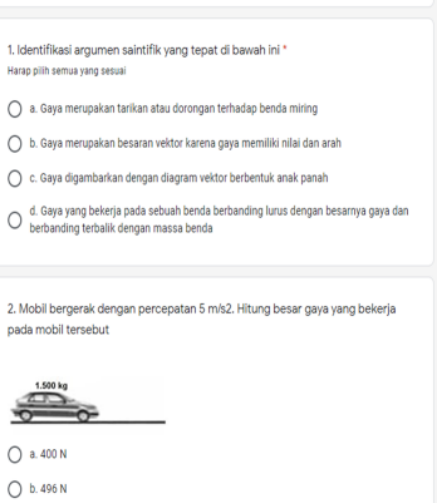

O $.496 \mathrm{~N}$

Gambar 1. Soal TOSLS menggunakan Aplikasi Google Form

Soal yang sudah dikembangkan oleh peneliti akan dikoreksi oleh validator ahli. Validator ahli dilakukan untuk melihat kelayakan instrument secara teoritis. Penentuan kualitas instrumen melibatkan 2 validator ahli. Instrument penilaian validasi berdasarkan aspek penilaian isi, konstruksi, dan bahasa. Penilaian isi meliputi isi atau konten soal, konstruksi meliputi pengembangan atau inovasi dari soal tersebut, sedangkan bahasa adalah keterbacaan soal oleh siswa. Hasil validitas instrument soal terdapat pada Tabel 2 di bawah ini

Tabel 2. Hasil Validasi Soal

\begin{tabular}{llcccc}
\hline & & \multicolumn{3}{c}{ Jumlah Soal } & \\
\cline { 3 - 5 } No & Validator & Valid & $\begin{array}{c}\text { Kurang } \\
\text { Valid }\end{array}$ & $\begin{array}{c}\text { Tidak } \\
\text { Valid }\end{array}$ & $\begin{array}{c}\text { Total } \\
\text { Soal }\end{array}$ \\
\hline 1 & $\begin{array}{l}\text { Dosen Ahli Penilaian } \\
\text { Pembelajaran }\end{array}$ & 33 & 7 & 0 & 40 \\
\hline 2 & Dosen Ahli Bidang IPA & 30 & 10 & 0 & 40 \\
\hline
\end{tabular}


Berdasarkan Tabel 2 bahwasanya hasil validasi soal oleh validator 1 yang merupakan dosen penilaian pembelajaran dan validator 2 yaitu dosen bidang IPA diperoleh rata-rata 30 soal yang valid sedangkan yang dinyatakan kurang valid terdapat 10 soal. Beberapa soal yang dinyatakan kurang valid terdapat pada sub indikator 3, 7, 8, dan 9. Salah satu soal yang terdapat pada sub indikator 3 yaitu "
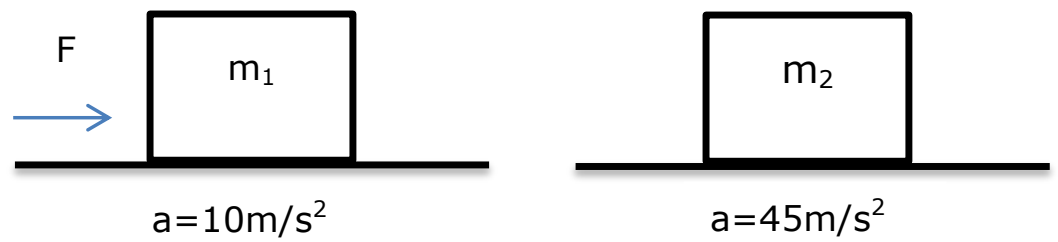

"Berdasarkan soal tersebut, hitung perbandingan $\mathrm{m}_{1}$ dan $\mathrm{m}_{2}$ ?"

Soal tersebut bertujuan agar siswa mampu menganalisis masalah sesuai dengan sub indikator 3. Berdasarkan hasil validasi soal, bahwasanya soal tersebut kurang valid, dikarenakan kurang adanya gambar yang digunakan untuk memperjelas soal tersebut. Maka dari itu soal tersebut ditambahi dengan adanya ilustrasi gambar. Soalsoal yang dianggap kurang valid kemudian direvisi ulang, sehingga soal tersebut bisa digunakan. Soal yang valid dan diujicobakan berjumlah 40 soal pilihan ganda yang telah direvisi, proses revisi soal membutuhkan waktu kurang lebih 3 hari sebelum ujicoba. Soal yang siap dipakai diketik menggunakan aplikasi Google Form, kemudian baru diujicobakan kepada siswa. Sebelum diujicobakan soal harus diuji reliabilitas sesuai dengan Tabel 3 di bawah. Bahwasanya produk soal yang siap digunakan harus melalui tahapan-tahapan salah satunya uji validitas dan reliabilitas, untuk melihat sejauh mana produk soal tersebut berkualitas dan memiliki tingkat akurasi yang tinggi. Peneliti telah melakukan pengembangan soal berdasarkan pada acuan dari pengembangan penelitian Gormally yang didapatkan koefisien alpha di bawah ini

Tabel 3. Nilai Koefisien Alpha

\begin{tabular}{cc}
\hline Ujicoba ke & Hasil \\
\hline 1 & 0,88 \\
\hline 2 & 0,83 \\
\hline 3 & 0,81 \\
\hline
\end{tabular}

Hasil reliabilitas dalam pengembangan diperoleh rata-rata 0,84. Hasil pengukuran dapat dikatakan reliable jika dalam beberapa kali pelaksanaan ujicoba diperoleh hasil pengukuran yang hampir sama. Tabel 3 menunjukkan bahwa nilai koefisien alpha tidak jauh berbeda. Hal ini dapat disimpulkan bahwasanya hasil pengukuran dari instrumen penilaian TOSLS dikatan reliable. Hal ini sesuai dengan Hayati (2016), jika hasil reliabilitas tinggi maka dikatakan instrument dapat dipercaya dan sah. Meskipun instrument itu telah digunakan oleh peneliti sebelumnya. Instrument dikatakan baik jika telah diuji berulang-ulang untuk meningkatkan kualitas instrument, karena hal ini akan berpengaruh terhadap nilai validitas dan reliabilitas. Instrumen soal yang dianggap kurang valid oleh validator ahli pada sub indikator 3, 7, 8 , dan 9 dan telah direvisi kemudian diujicobakan dan menghasilkan hasil baik pada ujicoba atau penerapan soal pada siswa, begitupun pada sub indikator 7 juga menghasilkan rata-rata yang memiliki kategori baik. Bahwasanya dapat diperoleh pembahasan bahwa soal yang semula kurang valid dan telah dilakukan proses revisi kemudian diujicobakan siswa mampu memahami soal tersebut sehingga hasil yang diperoleh skor tinggi. 
Tabel 4. Hasil Ujicoba

\begin{tabular}{ccccccc}
\hline \multirow{2}{*}{ Indikator $\begin{array}{c}\text { Sub } \\
\text { Indikator }\end{array}$} & \multicolumn{3}{c}{$\begin{array}{c}\text { Skor Total Rerata } \\
\text { Ujicoba }\end{array}$} & $\begin{array}{c}\text { Rata- } \\
\text { rata }\end{array}$ & Kategori \\
\cline { 2 - 5 } & 1 & 80,33 & 81,80 & 80,65 & 80,92 & $\begin{array}{c}\text { Sangat } \\
\text { baik }\end{array}$ \\
\hline I & 2 & 50,65 & 49,41 & 50,21 & 50,09 & $\begin{array}{c}\text { Kurang } \\
\end{array}$ \\
& 3 & 76,55 & 75,90 & 76,81 & 76,42 & Baik \\
& 4 & 58,40 & 56,22 & 59,87 & 58,16 & Cukup \\
& 1 & 41,78 & 40,20 & 40,77 & 40,91 & Kurang \\
& 2 & 65,12 & 66,24 & 66,89 & 66,08 & Baik \\
& 3 & 75,45 & 73,54 & 75,12 & 74,70 & Baik \\
& 4 & 53,88 & 52,67 & 53,55 & 53,36 & Kurang \\
& 5 & 65,11 & 64,36 & 65,50 & 64,99 & Cukup \\
& & & & & & \\
\hline
\end{tabular}

Berdasarkan Tabel 4, diperoleh rata-rata dari indikator I dan II hasil literasi sains adalah 62,84 masuk dalam kategori cukup. Skor tertinggi terdapat pada indikator 1 sub indikator siswa mampu mengidentifikasi argument saintifik yang tepat, sedangkan rata-rata terendah yaitu pada indikator II sub indikator siswa mampu membuat grafik yang dapat merepresentasikan data. Pengembangan instrument TOSLS berbasis daring yang dilakukan menggunakan google form. Implementasi pengembangan instrument TOSLS dilakukan 3 kali ulangan, dikarenakan digunakan untuk meningkatkan generalisasi. Pada ujicoba pertama skor tertinggi terdapat pada indikator siswa mampu mengidentifikasi argument saintifik yang tepat. Skor terendah terdapat pada indikator siswa mampu membuat grafik yang dapat merepresentasikan data. Pada ujicoba kedua skor tertinggi diperoleh pada indikator siswa mampu mengidentifikasi argument saintifik yang tepat. Skor terendah terdapat ada indikator membuat grafik yang dapat merepresentasikan data. Pada ujicoba ketiga skor tertinggi diperoleh pada indikator mengidentifikasi argument saintifik yang tepat. Skor terendah terdapat pada indikator membuat grafik yang dapat merepresentasikan data, setelah dilakukan wawancara dengan siswa hal ini dikarenakan siswa masih merasa kesulitan dalam membuat grafik yang sesuai dengan data yang sudah ditentukan. Hal ini kemudian dijadikan sebagai bahan evaluasi yang nantinya akan didiskusikan dengan guru ipa terkait indikator yang memiliki skor terendah. Evaluasi ini akan dijadikan sebagai evaluasi dalam pembelajaran di kelas, khususnya pada materi gaya. Dapat disimpulkan bahwa ujicoba pertama, kedua, dan ketiga sama. Kekurangan ini akan menjadi evaluasi tersendiri bagi guru mata pelajaran IPA.

Pemberian penilaian secara daring yang diberikan guru kepada siswa bisa menjadi acuan dalam evaluasi pembelajaran, hal ini dikarenakan bobotnya lebih besar dibandingkan dengan tugas. Namun, dalam kondisi pandemi ini aspek kejujuran siswa dalam mengerjakan soal menjadi permasalahannya. Siswa tidak bisa terpantau dengan seksama saat mengerjakan, dengan mudah siswa bisa mengakses google untuk mencari jawabannya. Menurut Damanik (2019) evaluasi pembelajaran daring menjadi kesulitan hampir semua pendidik. Hal ini terdapat pada sulitnya memberikan pengawasan saat evaluasi berlangsung, sulitnya menerapkan prinsip objektivitas, tidak mampu menerapkan nilai kejujuran.

Menurut Sari (2021), hasil risetnya menjelaskan bahwa proses pembelajaran selama pandemi membuat banyak temuan baru, salah satunya terkait dengan pembelajaran daring. Banyak tantangan ataupun kendala dalam pembelajaran ini, 
sehingga guru harus dituntut inovatif. Hal ini memberikan dampak pada guru karena kurang maksimal dalam penggunaan aplikasi daring, sehingga guru terjadi kekhawatiran dalam melakukan evaluasi pembelajaran. Maka dari itu penilaian memberikan dampak pada siswa terhadap pembelajaran daring. Menurut Mahirah (2017) penilaian sebagai bentuk evaluasi dapat mengetahui kompetensi yang telah dicapai selama pembelajaran. Misalkan dalam siswa memperoleh hasil yang memuaskan akan memberikan dampak reaksi yaitu mampu memotivasi siswa untuk lebih bersemangat dan bergairah dalam belajar. Jika hasil yang dicapai tidak memuaskan, maka siswa akan berusaha memperbaiki kegiatan belajarnya, akan tetapi guru dan orang tua harus kooperatif memberikan stimulus yang positif.

Dalam penelitian pengembangan ini, peneliti telah memperoleh nilai validitas dan reliabilitas yang baik, nilai reliabilitas dapat dikategorikan tinggi. Artinya instrument penilaian yang telah dikembangkan reliable dan valid, dengan demikian instrument untuk mengukur literasi sains pada siswa di SMP Negeri Srono yang telah diuji dan dapat dipercayai mampu mengukur literasi sains bagi siswa. Namun, dalam penelitian ini hanya melibatkan responden terbatas artinya hanya menggunakan responden 1 kelas untuk 1 sekolah. Hal ini perlu dilakukan suatu penelitian dengan skala yang lebih besar lagi, agar instrument ini lebih bagus serta nilai validitas dan reliabilitas semakin tinggi.

\section{KESIMPULAN}

Berdasarkan hasil ujicoba instrument yang telah dikembangkan bahwanya terdapat 40 butir soal yang layak digunakan sebagai instrument TOSLS, koefisien alpha menunjukkan nilai rata-rata 0,8 yang artinya instrument dapat dipercaya dan baik, hasil ujicoba diperoleh rata-rata skor 62,8 yang berarti cukup. Sehingga dapat disimpulkan bahwa instrument ini mampu untuk mengukur literasi sains.

\section{SARAN}

Perlu adanya tindak lanjut dalam mengembangkan produk penilaian atau instrument TOSLS agar dapat dimanfaatkan oleh guru IPA dalam penilaian literasi sains untuk kelas VIII. Dalam hal ini guru dapat mengembangkan instrument penilaian TOSLS pada materi dan pelajaran yang lain sebagai bentuk inovasi dalam evaluasi pembelajaran.

\section{DAFTAR PUSTAKA}

Arikunto, S. (2013). Dasar Penilaian Pendidikan Edisi Kedua. Jakarta: Bumi Aksara

Dewi dkk, (2016). Pengembangan Instrumen Penilaian Pembelajaran IPA untuk Memetakan Critical Thinking dan Practical Skill Peserta didik SMP. Program Studi Pendidikan Sains Program Pascasarjana Universitas Negeri Yogyakarta. Jurnal Inovasi Pendidikan IPA ISSN: 2406-9205, Online ISSN: 2477-4820

Fitria Hidayati, dkk. (2018). Penerapan Literasi Sains dalam Pembelajaran IPA di Sekolah Dasar untuk Meningkatkan Kemampuan Berpikir Kritis Siswa dalam Memecahkan Masalah. Jurusan PGSD universitas WR Supratman Surabaya. Seminar Nasional Pendidikan Banjarmasin 24 Maret 2018. ISBN: 978-602-648363-8

Gormally, Cara et al. (2012). Developing a Test of Scientific Literacy Skills (TOSLS); Measuring Undergraduates Evaluation of Scientific Information and Argument. CBE-Life Science Education, 11: 364-377.

Hayati, Salma. (2016). Validitas dan Reliabilitas Instrumen Pengetahuan Pembelajaran Aktif, Kreatif, dan Menyenangkan (PAKEM) Menggunakan Model RASCH. Jurnal IImiah DIDAKTIKA Februari Vol 16 No 2 Hal: 169-179 
Imania Kuntum An Nisa,dkk. (2019). Rancangan Pengembangan Instrumen Penilaian Pembelajaran Berbasis Daring. Jurnal PETIK Volume 5, Nomor 1, Maret 2019. PISSN : 2460-7363 e-ISSN : 2614-6606

Mahirah, B. (2017). Evaluasi Belajar Peserta didik (Siswa). Fakultas Tarbiyah dan Keguruan UIN Alauddin Makassar. Jurnal Iddarah, Vol. 1 No. 2, Desember 2017.

Rabukit Damanik. (2019). Evaluasi Program Pembelajaran Matematika Dengan Pendekatan Kirkpatrick. Jurnal Serunai Administrasi Pendidikan Vol 8, No. 2, Oktober 2019. e-ISSN 2620-9209.

Sugiyono. (2015). Metode Penelitian Kuantitatif, Kualitatif dan R \& D. Bnadung:Alfabeta.

Sugiyono. (2016). Metode Penelitian Kuantitatif, Kualitatif dan R \& D. Bandung: Alfabeta.

Sulthon. (2016). Pembelajaran IPA yang Efektif dan Menyenangkan Bagi Siswa Madrasah Ibtidaiyah (MI). STAIN Kudus, Jawa Tengah Indonesia. Jurnal ELEMENTARY Vol.4 No.1 Januari 2016.

Sari, Ria Puspita. dkk. (2021). Dampak Pembelajaran Daring Bagi Siswa Sekolah Dasar Selama Covid-19. Jurnal Ilmiah Kependidikan Volume 2-Nomor 1, April 2021, 9-15.

Vidya Putri Sukmasari, dkk. (2017). Pengembangan Penilaian Proyek Pembelajaran IPA Berbasis Discovery Learning untuk Mengukur Keterampilan Pemecahan Masalah. Program Studi Pendidikan Sains Program Pascasarjana Universitas Negeri Yogyakarta. Jurnal Inovasi Pendidikan IPA, 3 (1) Tahun 2017 No 101110.

Winarno, M.E. 2011. Panduan Metodologi Penelitian dalam Pendidikan Jasmani. Malang: Media Cakrawala Utama Press. 